\title{
ИНТЕГРАТИВНОЕ ПРАВОПОНИМАНИЕ И ГЕНЕТИЧЕСКИЙ МЕТОД В ЮРИДИЧЕСКОЙ НАУКЕ
}

\begin{abstract}
Аннотация: Статья посвящена проблемам формирования теории интегративного правопонимания в России, особенностям развития генетического метода в русской социологической школе права, анализу теоретической позици Б.А. Кистяковского по поводу реальности объективного права и роли истинного понимания «общественности» 6 вопросе понимания природы права. В статье уделяется внимание содержанию генетического метода познания и характеру историографической ситуаиии в российской правовой науке на рубеже XIX - XX вв. Особое значение в формировании генетического метода в отечественной сочиологии права в творчестве Б.А. Кистяковского сыграла интерпретационная схема, подразумевающая логическую взаимосвязь между реальностью объективного права и нормативной системой общества, соииальной нормой, образующей общество. В рамках генетического метода познание права возможно прежде всего на основе изучения проблемы правогенеза, исследования природы права, порождающей его операџиональность. К проблеме происхождения права апеллировали большинство из представителей русской школы интегративного правопонимания (М.М. Ковалевский, С.А. Муромиев, Б.А. Кистяковский). Современное состояние дискуссии о типах правопонимания, с одной стороны, характеризуется возросшим интересом к проблеме выработки непротиворечивой теории интегративного правопонимания, с другой, отсутствием серьезного теоретического интереса к деятельностной, практической традиции изучения права в рамках генетического метода, наметившейся в российском правоведении в конще XIX-начале XX вв.
\end{abstract}

Abstract: This article considers the problems of establishing a theory of integrated legal consciousness in Russia, outlines the particulars of developing the genetic method in the Russian school oflegal sociology, and presents an analysis of the theoretical position of Bogdan Kistyakovsky in relation to the possibility of objective law and the role of the inherent concept of the "public sphere" when discussing the nature of law. The article focuses on the essence of the genetic method of learning and the nature of the historiographical situation in Russian legal science at the turn of the $20^{\text {th }}$ century. For Kistyakovsky, the hermeneutical schema was of particular importance in the formation of the genetic method in Russian legal sociology. This alludes to the logical relationship between the reality of objective laws and the normative system of society - the social norms which form society. The framework of the genetic method gives rise to an understanding of law primarily through the study of the problems of the origins of law: the study of the nature of law which brings about its operationality. The problems of the origins of law were touched upon by the majority of the representatives of the Russian school of integrative legal consciousness (Maxim Kovalevsky, Sergey Muromtsev, Bogdan Kistyakovsky). On the one hand, contemporary discussion of the types of legal consciousness is characterized by an increased interest in the problem of generating a consistent integrative theory of legal consciousness. On the other hand, there is a lack of serious theoretical interest in the pragmatic and practical tradition of the study of law using the genetic method, as outlined in Russian jurisprudence in the late 19th and early $20^{\text {th }}$ centuries.

Ключевые слова: нормативная теория права, соииологическая школа права, автономность права, происхождение права, социальная норма, объективное право, генетический метод, интегративное правопонимание, научно-интегративньй подход, операциональность права

Keywords: normative theory of law, school of legal sociology, legal autonomy, origins of law, social norms, objective law, genetic method, integrated legal consciousness, scientific-integrated approach, operationality of law

а протяжении длительного времени отечественные правоведы отмечают крайне неудовлетворительное состояние развития юридической науки. В начале XX в. вышли в свет две фундаментальные работы выдающихся русских юристов - П. Новгородцева ${ }^{1}$ и Б.А. Кистяков-

\footnotetext{
${ }^{1}$ См. Новгородиев П.И. Кризис современного правосознания: Введение в философию права. Вып. 2 - М.: Типо-лит. т-ва И. Н. Кушнерев и Ко, 1909.
} 
ского ${ }^{2}$, содержащие в самом названии указание на кризис в юриспрудеции. На рубеже XX-XXI вв. А.В. Поляков отметил, что в вопросе о выработке «непротиворечивой, работающей» теории права наметился регресс, и констатировал кризис современного российского теоретического правосознания ${ }^{3}$. В.М. Сырых, автор исследования «История и методология юридической науки» ${ }^{4}$, выделяя снижение уровня качества научных публикаций в качестве одной из определяющих особенностей современного этапа развития российской юридической науки и характеризуя негативные последствия методологического плюрализма в правоведении, пишет о том, что сама «огульная критика диалектико-материалистического метода» является следствием повторения «теоретических и методологических ошибок, допущенных советскими правоведами в критикуемый период» ${ }^{5}$. В.В. Ершов, отстаивающий на протяжении последнего десятилетия идеи интегративного правопонимания, на примере анализа ведущих проблем российского права сформулировал вывод о невозможности практического применения теоретических положений представителей большинства из известных типов правопонимания, а также обосновал критику концепции «широкого» понимания права, содержащую на уровне исследовательской программы необоснованное расширение методологических рамок и восходящей к легизму ${ }^{6}$.

Современное состояние дискуссии о типах правопонимания, с одной стороны, характеризуется возросшим интересом к проблеме выработки непротиворечивой теории интегративного правопонимания, а с другой, отсутствием серьезного теоретического интереса к деятельностной, практической традиции изучения права в рамках генетического метода, наметившейся в российском правоведении в конце XIX-начале XX вв.

${ }^{2}$ См. Кистяковский Б.А. Кризис юриспруденции и дилетантизм в философии // Юридический вестник. 1914, кн. 5.

${ }^{3}$ Поляков A.B. Петербургская школа философии права и задачи современного правоведения // Правоведение. - 2000. - № 2. С. 4.

${ }^{4}$ Colpblx B.M. История и методология юридической науки: учебник. - М.: Норма: ИНФРА-М, 2012.

${ }^{5}$ Cырых B.M. История и методология юридической науки: учебник. - М.: Норма: ИНФРА-М, 2012. С.199-200.

${ }^{6}$ Ершов В.B. Российское право с позиции легизма и интегративного правопонимания // Российское правосудие. - 2011 - № 10. С.5-6. Данная статья является одной из трех статей проф. В.В. Ершова, объединенных единой проблемой анализа наиболее дискуссионных теоретических и практических проблем международного и внутригосударственного права.
В полной мере содержание наметившегося методологического поворота отразилось в тезисах участников Седьмых философско-правовых чтений памяти академика В.С. Нерсесянца, проходивших в Институте государства и права Российской академии наук. Интегративное, интегральное, синтезное правопонимание в теории права представляло сквозную тему данной конференции. Так, например, Е.В. Тимошина, утверждая первенство интегративного анализа в работах Л.И. Петражицкого по отношению к синтетическим «опытам» А.С. Ященко, отметила, что вопрос формирования «интегральной, синтетической теории» не связан с проблемой «формулирования многостороннего» или комбинационного определения понятия права» (следует заметить, в полной мере это относится и к теории Л.И. Петражицкого), данная теория не может развиваться «исключительно на основании анализа определения понятия права, но должна относиться ко всей системе логически взаимосвязанных теоретических утверждений» ${ }^{7}$. Подобная логическая связь может образовываться только на основе применения научного метода, являющегося основанием интегральной теории.

Важным аспектом развития темы интегральной теории правопонимания является поиск ее идейных предпосылок. По мнению И.Ф. Мачина, теологическая школа права, школа естественного права, школа юридического позитивизма, историческая, социологическая, психологическая школы права избирали различные источники генерации права, и в современных условиях, применяя достижения философии Аристотеля, Фомы Аквинского можно добиться нового интегративного правопонимания ${ }^{8}$.

Безусловно, следует различать понятия «интегративный», «интегральный». Когда речь идет об интегративном правопонимании, подразумевающем определенный результат, «работу» интегральной теории, то справедливо использование термина «интегративный». Рассматривая элементы интегральной теории,

\footnotetext{
${ }^{7}$ Тимошина Е.В. Идея «синтеза» в российской теории права и проблема интегральной юриспруденции // Энциклопедия правоведения или интегральная юриспрудеция? Проблемы изучения и преподавания». Седьмые философско-правовые чтения памяти академика В.С. Нерсесянца. Тезисы участников. - М.: Российская секция международной ассоциации правовой и социальной философии, 2012. С.14.

${ }^{8}$ Мачин И.Ф. Интегративная юриспруденция и интегративное понятие права: проблема соотношения // Энциклопедия правоведения или интегральная юриспруденция? Проблемы изучения и преподавания». Седьмые философско-правовые чтения памяти академика В.С. Нерсесянца. Тезисы участников. - М.: Российская секция международной ассоциации правовой и социальной философии, 2012. С.16-17.
} 
DOI: $10.7256 / 1811-9018.2013 .11 .10117$

При цитировании этой статьи сноска на dоі обязательна

\section{Право и политика $11(166) \cdot 2013$}

мы должны ориентироваться на понятие «интегратор».

В работах Б.В. Ахлибинского описаны три уровня интеграции, которые необходимы для разработки теоретической модели. К ним относятся: уровень эмпирический (описательный), который объединяет фактические сведения; уровень теоретический, в рамках которого синтезируются современные фундаментальные теории; уровень методологический, который интегрирует основные идеи различных методологических направлений. Кроме того, он характеризует интеграцию как единство трех процессов: а) компоненты множества вступают между собой в определенные связи (при этом каждый компонент первоначально может существовать независимо от этих связей, сохраняя важные качественные характеристики); б) элементы, входящие в целостность, сами качественно изменяются (вне взаимодействия с другими элементами, каждый из них теряет приобретенные новые качественные характеристики); в) конкретные компоненты настолько меняются в результате связи с другими компонентами, что не могут существовать вне этой связи ${ }^{9}$.

А.Д.Урсул, известный специалист в области методологических проблем теории информации, выделяет пять ступеней интеграции: совокупность (элементы объединяются на основе какого-то признака); комплексность как начальная форма синтеза; упорядоченность как появление отношения порядка между элементами; организация как возникновение новых признаков, отсутствовавших ранее (данные признаки и свойства возникают при появлении связей между объединенными элементами); система как вершина объединения, характеризующаяся образованием целостного единства в результате нарастания связей ${ }^{10}$.

В.Г. Графский одним из первых обратил внимание на Б.А. Кистяковского как представителя интегративного правопонимания. Он указал на методологическую и исследовательскую незавершенность интегративного «проекта» ${ }^{11}$. Развитие генетического метода в рамках русской социологической школы права связывается с именем М.М. Ковалевского ${ }^{12}$. Применительно к ин-

\footnotetext{
${ }^{9}$ Ахлибинский Б.В. Категориальный аспект понятия интеграции // Диалектика как основа интеграции научного знания. - Л.: Изд-во ЛГУ, 1984. - Вып. ХІІ. С. 53.

${ }^{10}$ Урсул А.Д. Интегративно-общенаучные тенденции и философия. Вопросы философии. -1977. - № 1. С. 25.

${ }^{11}$ Графский В.Г. История политических и правовых учений : учебник. - 3-е изд., доп. - М.: Норма, 2009. С.664.

${ }_{12}$ Апанасевич О.О. М.М. Ковалевский о предмете и методе генетической социологии права // Право и политика. - 2008. - № 2. C. 285-290
}

тегративному правопониманию можно говорить об использовании авторами в процессе дискуссий отдельных элементов генетического метода и формировании определенной деятельности, практической традиции изучения права, связанной с его историко-генетическими, логическими, системными основаниями. В 2006 г. проанализировал содержание правовой системы с позиций генетического подхода А.К. Черненко ${ }^{13}$.

Генетический подход в праве подразумевает способ (метод) исследования социально-правовых явлений и процессов, основанный на анализе причин, условий, факторов (среды) их происхождения и эволюционного развития ${ }^{14}$. Генетический метод прежде всего ориентирует исследователя на рассмотрения первоначальных условий развития, его основополагающих этапов и основных тенденций. Распространение генетического метода в науке в конце XVIII - начале XIX вв. способствовало становлению генетической психологии, генетической социологии. Немаловажно, что генетический анализ использовался при изучении ценностных установок. Структурно-функциональный анализ и генетический анализ нашли свое отражение в марксизме.

Сегодня в России постепенно растет интерес к теории интегративного правопонимания. Г.В. Мальцев, критикуя представителей аналитических направлений исследования права за подмену проблематики «нормативной теории права поисками «метаюридических конструкций», отмечал, что «нормативная проблематика ... является сейчас наименее разработанной» и видел причины такого положения в «невольных» издержках «в целом позитивного процесса углубляющейся специализации наук о морали, праве, политике...» ${ }^{15}$. Для того, чтобы «указанные издержки не могли возрастать, отмечает Г.В. Мальцев, необходимо сохранять и четко проводить идею единства, всеобщностей и взаимосвязей, действующих в обществе нормативнорегулятивных систем. Когда исследователь утрачивает ощущение этого единства и этих связей, когда он не видит того, что предмет его изучения - мораль, политика или право - всего лишь часть широко определяемого целостного порядка регулирования в обществе и берет

\footnotetext{
13 Черненко А.К. Теоретико-методологические аспекты формирования правовой системы общества. Дисс. на соискание ученой степени доктора юридических наук. - М.: 2006.

${ }^{14}$ Гойман-Калинский И.В., Иванеи Г.И., Червонюк В.И. Элементарные начала общей теории права: Учебное пособие для вузов / Под общей ред. д-ра юрид. наук, проф. В.И. Червонюка. - М.: КолосС, 2003. С.26.

${ }^{15}$ Мальцев Г.В. Нравственные основания права. - Москва.: Изд-во СГУ, 2008. С.195.
} 
их как сферы только специфического, не дублируемого другими системами социального содержания, возникает опасность двоякого рода - неадекватного познания данного регулятора, а также слабого внимания ко всей проблематике, связанной с организацией социального регулирования в целом» ${ }^{16}$

Указывая на значимость подобных принципов исследования права, близких теоретическим основаниям историко-генетического метода ${ }^{17}$, он обращает наше внимание и на важность «научно-интегративного подхода к изучению соционормативной культуры» ${ }^{18}$. При этом Г.В. Мальцев указывает, по сути, на операциональные процедуры, характерные для генетического метода. Так, например, он пишет: «Мы убеждены, что изучение морали и права следует начинать не с них самих, а с предварительного исследования сущностных, структурных и функциональных проблем соционормативной культуры общества, представленной рядом нормативно-регулятивных систем, способов регуляции социальных отношений, поведения, деятельности людей» ${ }^{19}$. Именно такие исследования требуют, по его мнению, научно-интегративного подхода.

Очень важно сохранить представление о том, что, анализируя процесс развития права, мы говорим об обществе не как о каком-то искусственном продукте исследования ученых, не как о какой-то исследовательской схеме, а как о живой, действующей системе, которая формируется в результате творческого развития, превращения в норме общества в общество, когда в результате коллективной общественной деятельности, развития интеллектуальных усилий человечества происходит выделение определенного общественного содержания в качестве нормы.

О важности подобной исследовательской традиции изучения права писал Б.А. Кистяковский. «...Мы должны сразу указать на то, что ни психологическое, ни нормативное понимание права, поскольку они последовательно рассматривают право лишь как элемент сознания, или только как продукт человеческого духа, не могут дать удовлетворительного ответа на вопрос о том, что такое объективное право. Оба эти воззрения на право при односторонней разработке их исключительно в свойственном каждому из них

\footnotetext{
${ }^{16}$ Мальцев Г.В. Указ.соч. С.196.

17 Одним из первых попытался охарактеризовать генетический метод, назвав его историко-генетическим методом, был известный русский юрист, социолог М.М. Ковалевский.

${ }^{18}$ Мальиев Г.В. Указ.соч. С.183.

${ }^{19}$ Мальиев Г.В. Указ.соч. С.183.
}

направлении необходимо приводят в конце концов к отрицанию объективного права как такового. Они придают объективному праву такой смысл, который совершенно не соответствует его истинному значению (выделено мною - Д.Л.) На место твердой основы общественного порядка, создаваемого системой положительного права, они ставят ряд переживаний и их объективирование. И психологическое, и нормативное понимание права в этом случае солидарны; они только каждое по-своему толкуют сущность переживаний, образующих право» ${ }^{20}$.

Полемизируя с Л.И. Петражицким, Б.А. Кистяковский высказывает еще один тезис о развиваемом им генетическом методе познания права. Он пишет о том, что «в основание своей теории права Л.И. Петражицкий кладет своеобразное учение об образовании научных понятий». Указав в начале работы «Реальность объективного права» на «общественность» как особого рода связь личности с обществом, Б.А. Кистяковский старается показать еще одну «ошибку» Л.И. Петражицкого и его сторонников. Выводя объективность права как наиболее истинного состояния из внутренних психических переживаний большинства людей, рассматривая объективность права через такое внутреннее чувство, они тем самым выводили общество и его структуру за скобки определения нормы, превращая процесс развития права и его постижения в развертывание понятийного аппарата правовой науки, активно пользующейся, аппелирующей к наблюдениям за человеческой психикой.

Благодаря такому методологическому выбору Б.А. Кистяковскому удается сформировать особую теоретическую позицию, когда феномен права как выражение генезиса, происхождения права не только является средоточием социальной, психической, государственно-организационной и нормативной сущности права, но и представляет собой общественную ценность, императив, внутренне содержащий возможность социального возрождения на ниве законности и правопорядка. Важно отметить, что этот призыв сочетается с категорическим требованием Богдана Александровича на фоне наметившегося методологического разнообразия и выделения новых областей юридического знания хранить «самобытность и автономность» права, сопровождается указанием на то, что «социологическое и психологическое направления в юриспруденции стоят, несомненно,

\footnotetext{
${ }^{20}$ Кистяковский Б.А. Реальность объективного права // Социальные науки и право. - М.: Издание М. и С. Сабашниковых. 1916. С.337.
} 
DOI: $10.7256 / 1811-9018.2013 .11 .10117$

При цитировании этой статьи сноска на ооі обязательна

\section{Право и политика $11(166) \cdot 2013$}

на методологически ложном пути, когда они хотят заменить науку о праве социологией или учением о правовой психике» ${ }^{21}$.

Утверждая ложность иных путей познания права, он пытается донести до читателя главное - хотя право является продуктом общественной, исторической жизни, его «нельзя растворять в тех сферах явлений, с которыми оно соприкасается и связано» ${ }^{22}$. Он апеллирует к пониманию особой операциональной формы права и к необходимости специальной теоретической позиции для ее рассмотрения. Пафос вчерашнего борца с самодержавием преобразуется в пафос и торжество методолога, познавшего истинное значение природы права для общества и науки.

В качестве важнейшей задачи юристов методолог российского права рассматривал «определенность, прочность и устойчивость права» и видел в этом «высшее благо» для современной ему России. Особенно он выделял роль суда в соблюдении блага Отечества. «... Суд должен быть у нас прежде всего слугой устойчивости права, - писал Б.А. Кистяковский. Исключительную важность этой миссии сам суд должен сознавать и добровольно ограничивать себя даже в тех случаях, где он мог бы решить вопрос по усмотрению, но где это не безусловно необходимо» ${ }^{23}$.

Применяя логику историко-генетического метода, Б.А. Кистяковский резко возражал заимствованию западных воззрений по поводу расширения сферы судейского усмотрения. Он считал подобные устремления «искусственными и наносными» ${ }^{24}$. Поэтому методолог делал вывод о целесообразности усовершенствования «действующего права путем законодательства, чем путем других форм правотворчества» ${ }^{25}$.

Вводя в пространство основополагающей методологической работы «Реальность объективного права», Б.А. Кистяковский указывает на особое отношение человека к связи с обществом, то есть тот алгоритм, который интегрирует человека в состояние взаимодействия с обществом. «...Конечно, не идеальная сфера нравственности, а более реальная область права придает общественности этот характер», - пишет Б.А. Кистяковский. Господство общественности над личностью создается правом, главным образом, благодаря его свойству как бы извне вторгаться в жизнь человека.

\footnotetext{
${ }^{21}$ Кистяковский Б.А. Реальность объективного права. С.658.

22 Указ.соч. С.658.

23 Там же.

24 Там же.

${ }^{25}$ Там же.
}

Этому способствует и государственная организация, направленная на осуществление правовых норм, и сила общественного мнения, отстаивающая ненарушимость основных правовых принципов, и, наконец, укоренившиеся побуждения в каждой отдельной психике, постоянно всплывающие на поверхность сознания и предъявляющие к нему властные требования ${ }^{26}$.

С другой стороны, сознавая значимость подобного «общественного чувства», Б.А. Кистяковский полностью отрицает только психологический или только нормативный путь понимания права. Постулируя точку зрения об «объективности права», он, прежде всего, старается указать на операциональность права ${ }^{27}$. Иными словами, объективность права у Б.А. Кистяковского связана с объективностью общества, с тем, что общество представляет конкретный феномен, обладающий верифицируемыми в ходе исследования признаками. Когда мы постулируем мысль о дореволюционной школе интегративного прававопонимания, видим в современном развитии правовых теорий продолжение отечественной школы права, мы опираемся на ряд фундаментальных признаков. Первая теоретически значимая позиция заключается в том, что прежде чем доказывать самостоятельное значение бытия права, русские юристы и методологи опирались на значимое для них понятие объективности общества.

Полемизируя с Л.И. Петражицким и завершая работу «Реальность объективного права», он замечает: «У нас еще в конце семидесятых годов С.А. Муромцев указал на то, что основная задача научного познания права заключается в исследовании причинных соотношений в процессе созидания права». Сам Л.И. Петражицкий, к сожалению, не упоминает об этой русской традиции в науке о праве» ${ }^{28}$. Таким образом, Б.А. Кистяковский определяет еще одну черту генетического метода: познание права возможно, прежде всего, на основе изучения проблемы правогенеза, той природы права, которая порождает операциональность права, а для этого необходимо изучение указанных С.А. Муромцевым

\footnotetext{
${ }^{26}$ Там же. С.258.

${ }^{27} \mathrm{~B}$ современных исследованиях термин «операциональный» применяется в целом ряде областей научного знания. Применительно к праву речь идет о действии права, его функциональных, операциональных возможностях, тесно взаимосвязанных с системными основаниями. Однако Б.А. Кистяковский, как нам представляется, дает очень удачное описание, вектор изучения подобной операциональности права, ссылаясь на С.А. Муромцева.

${ }^{28}$ См. Кистяковский Б.А. Реальность объективного права // Социальные науки и право. -М.: Издание М. и С. Сабашниковых. 1916. C.
} 
DOI: $10.7256 / 1811-9018.2013 .11 .10117$

При цитировании этой статьи сноска на dоі обязательна

Правовая и политическая мысль

«причинных соотношений». Именно в этом заключается вторая теоретически значимая позиция рассмотрения генетического метода. Большинство из представителей русской школы интегративного правопонимания (М.М. Ковалевский, С.А. Муромцев, Б.А. Кистяковский) апеллировали к теме происхождения права как главной конституирующей теме развития права и государства

По-видимому, речь может идти об особой историографической ситуации, сформировавшейся в российском правоведении и характеризующейся следующим: на рубеже XIX-начала XX вв., в преддверии революции в России сформировалась школа интегративного правопонимания, но ее развитие не было завершено, и только в последнее десятилетие XX в. начинается возрождение отечественной школы интегративного правопонимания. С другой стороны, подобная незавершенность связана с тем, что представители русской социологической школы права С.А. Муромцев, Б.А. Кистяковский не успели на должном уровне обобщить представления о методе интегративной теории правопонимания.

Сегодня мы можем наблюдать возрождение школы интегративного правопонимания. Отрадно, что она получила развитие в Российской академии правосудия. Примечательно, что данная школа формируется объективно, воссоздавая тот путь, который был утерян в силу исторических обстоятельств. Ее основные направления и исследовательские принципы формируются, восходя к принципам и приемам дореволюционной науки.

Теоретические построения Б.А. Кистяковского вполне современны и взаимосвязаны с методологическими позициями в современном российском правоведении. Б.А. Кистяковский отмечал практическое значение истинного осознания «реальности объективного права». Современное состояние дискуссии о типах правопонимания, с одной стороны, характеризуется возросшим интересом к проблеме выработки непротиворечивой теории интегративного правопонимания, с другой, отсутствием серьезного теоретического интереса к деятельностной, практической традиции изучения права в рамках генетического метода, наметившейся в российском правоведении в конце XIX- начале XX вв.

\section{Библиография:}

1. Апанасевич О.О. М.М. Ковалевский о предмете и методе генетической социологии права // Право и политика. - 2008. - № 2. С. 285-290.
2. Гойман-Калинский И.В., Иванец Г.И., Червонюк В.И. Элементарные начала общей теории права: Учебное пособие для вузов / Под общей ред. д-ра юрид. наук, проф. В.И. Червонюка. М.: КолосС, 2003. 544 с.

3. Графский В.Г. История политических и правовых учений : учебник. - 3-е изд., доп. М.: Норма, 2009. $736 \mathrm{c.}$

4. Ершов В.В. Российское право с позиции легизма и интегративного правопонимания // Российское правосудие. - 2011 - № 10. С. 5-22.

5. Кистяковский Б.А. Кризис юриспруденции и дилетантизм в философии // Юридический вестник. 1914, кн. 5. С. 70-106.

6. Кистяковский Б.А. Реальность объективного права // Социальные науки и право. М.: Издание М. и С. Сабашниковых, 1916. 704 с.

7. Мальцев Г.В. Нравственные основания права. М.: Изд-во СГУ, 2008. 552 с.

8. Новгородцев П.И. Кризис современного правосознания: Введение в философию права. Вып. 2. М.: Типо-лит. т-ва И.Н. Кушнерев и Ко, 1909.

9. Поляков А.В. Петербургская школа философии права и задачи современного правоведения // Правоведение. - 2000. - № 2.

10. Сырых В.М. История и методология юридической науки: учебник. М.: Норма: ИНФРА-М, 2012.

11. Тимошина Е.В. Идея «синтеза» в российской теории права и проблема интегральной юриспруденции // Энциклопедия правоведения или интегральная юриспрудеция? Проблемы изучения и преподавания». Седьмые философско-правовые чтения памяти академика В.С. Нерсесянца. Тезисы участников. М.: Российская секция международной ассоциации правовой и социальной философии, 2012.

12. Черненко А.К. Теоретико-методологические аспекты формирования правовой системы общества. Дисс. на соискание ученой степени доктора юридических наук. М.: 2006.

\section{References (transliteration):}

1. Apanasevich O.O. M.M. Kovalevskii o predmete $\mathrm{i}$ metode geneticheskoi sotsiologii prava // Pravo i politika. - 2008. - № 2. S. 285-290.

2. Goiman-Kalinskii I.V., Ivanets G.I., Chervonyuk V.I. Elementarnye nachala obshchei teorii prava: Uchebnoe posobie dlya vuzov / Pod obshchei red. d-ra yurid. nauk, prof. V.I. Chervonyuka. M.: KolosS, 2003. 544 s. 
DOI: $10.7256 / 1811-9018.2013 .11 .10117$

При цитировании этой статьи сноска на dоі обязательна

\section{Право и политика 11 (166) • 2013}

3. Grafskii V.G. Istoriya politicheskikh i pravovykh uchenii : uchebnik. - 3-e izd., dop. M.: Norma, 2009. 736 s.

4. Ershov V.V. Rossiiskoe pravo s pozitsii legizma i integrativnogo pravoponimaniya // Rossiiskoe pravosudie. - 2011 - № 10. S. 5-22.

5. Kistyakovskii B.A. Krizis yurisprudentsii i diletantizm v filosofii // Yuridicheskii vestnik. 1914, kn. 5. S. 70-106.

6. Kistyakovskii B.A. Real'nost' ob'ektivnogo prava // Sotsial'nye nauki i pravo. M.: Izdanie M. i S. Sabashnikovykh, 1916. 704 s.

7. Mal'tsev G.V. Nravstvennye osnovaniya prava. M.: Izd-vo SGU, 2008. $552 \mathrm{~s}$.

8. Novgorodtsev P.I. Krizis sovremennogo pravosoznaniya: Vvedenie v filosofiyu prava. Vyp. 2. M.: Tipo-lit. t-va I.N. Kushnerev i Ko, 1909.
9. Polyakov A.V. Peterburgskaya shkola filosofii prava $\mathrm{i}$ zadachi sovremennogo pravovedeniya // Pravovedenie. -2000 . - № 2 .

10. Syrykh V.M. Istoriya i metodologiya yuridicheskoi nauki: uchebnik. M.: Norma: INFRA-M, 2012.

11. Timoshina E.V. Ideya «sinteza» v rossiiskoi teorii prava i problema integral'noi yurisprudentsii // Entsiklopediya pravovedeniya ili integral'naya yurisprudetsiya? Problemy izucheniya i prepodavaniya». Sed'mye filosofsko-pravovye chteniya pamyati akademika V.S. Nersesyantsa. Tezisy uchastnikov. M.: Rossiiskaya sektsiya mezhdunarodnoi assotsiatsii pravovoi i sotsial'noi filosofii, 2012.

12. Chernenko A.K. Teoretiko-metodologicheskie aspekty formirovaniya pravovoi sistemy obshchestva. Diss. na soiskanie uchenoi stepeni doktora yuridicheskikh nauk. M.: 2006. 